\title{
Quantification of Particulate Emission from Construction Activities Using Discrete-Event Simulation
}

\author{
Charinee Limsawasd", Nathee Athigakunagorn \\ Department of Civil Engineering, Faculty of Engineering, Kamphaeng Saen, Kasetsart University, Nakhon Pathom, Thailand
}

Received December 25, 2021; Revised February 7, 2022; Accepted February 25, 2022

\section{Cite This Paper in the following Citation Styles}

(a): [1] Charinee Limsawasd, Nathee Athigakunagorn, "Quantification of Particulate Emission from Construction Activities Using Discrete-Event Simulation," Civil Engineering and Architecture, Vol. 10, No. 2, pp. 703-714, 2022. DOI: 10.13189/cea.2022.100225.

(b): Charinee Limsawasd, Nathee Athigakunagorn (2022). Quantification of Particulate Emission from Construction Activities Using Discrete-Event Simulation. Civil Engineering and Architecture, 10(2), 703-714. DOI: 10.13189/cea.2022.100225.

Copyright $\bigcirc 2022$ by authors, all rights reserved. Authors agree that this article remains permanently open access under the terms of the Creative Commons Attribution License 4.0 International License

\begin{abstract}
Construction activities generate a significant number of airborne pollutants. Particulate matter (PM) is one of the important emissions arising throughout construction, especially in large-scale projects due to the utilization of heavy-duty equipment. Nevertheless, there is no competent approach that is capable of quantifying PM emissions from construction equipment operations at the pre-planning stage. Therefore, the development of a sufficiently accurate and simple quantification model is pressingly needed as the first step to help construction planners in identifying potential mitigation opportunities toward sustainable construction. This paper introduces a PM emission estimation model in an integrated application with a discrete-event simulation (DES) technique, namely EZStrobe. The model is developed with the aim of improving the current body of knowledge in the aspects of simplicity and practicality to address the restriction of input data availability in the initial phase of construction projects. A case study of a real highway project in Thailand is used to demonstrate the use and performance of the developed model in evaluating the environmental impacts in terms of diesel exhaust emissions. The findings identify critical construction activities and factors potentially affecting the environment. This approach enables construction planners to obtain a holistic, sustainable viewpoint in efficiently managing existing construction resources.
\end{abstract}

Keywords EZStrobe, Particulate Matter (PM), Highway Construction, Construction Equipment, Environmental Impact, Airborne Pollutant

\section{Introduction}

Air pollution, especially in urban areas, has become a serious environmental problem as a result of fast-growing industrialization and urbanization. Many medical documents and research studies have reported the correlation between PM and severe health effects in hospital emergency room visits [1], including inflammation, oxidative stress, lung and heart malfunction [2], as well as tissue damage [3]. According to the U.S. Environmental Protection Agency (US EPA), fugitive dust and engine exhaust are parts of major anthropogenic sources of total PM emissions in the USA [4]. The massive number of pollutants in the atmosphere is mainly contributed by roading and construction activities. Generally, $\mathrm{PM}_{10}$ and $\mathrm{PM}_{2.5}$ have been considered as the two common particle sizes widely investigated nowadays. Studies have recognized that the emissions from roadway construction could contribute up to $59 \%$ and $77 \%$ of the total life cycle amounts of $\mathrm{PM}_{10}$ and $\mathrm{PM}_{2.5}$, respectively [5], with their main contributors being from construction-oriented, heavy-duty equipment [6]. Accordingly, there is a pressing need to develop a powerful method that can provide reliable estimates of construction equipment emissions during construction activity.

Nevertheless, there is a scarcity of information on a competent approach for PM emissions quantification at the pre-planning stage, due to a limitation of data availability prior to the actual construction operation. As such, a PM emission estimation model is developed in this paper based on an integrated application of the 
discrete-event simulation (DES) technique. Several past studies have mentioned DES as a powerful tool in simulating the complexities of construction operations [7-9] and its application for solving construction-oriented research problems [10-12]. Although, there have been a few studies using DES in evaluating pollutant emissions in construction projects [13-16], no research work has focused mainly on PM emissions. In addition, as there are several DES languages designed for construction-research problem solving due to different purposes and levels of analysis, EZStrobe was adopted here because of its capabilities of simplicity and minimal effort-needed [17] compared to other DES tools.

This paper aims to develop a PM emission estimation model that facilitates construction planners in evaluating environmental impacts due to construction equipment operations. Using the model at the initial stage can further contribute to more efficient decision making for planning construction equipment fleet usage prior to a project's commencement, to reduce the PM emissions from the operation site. Figure 1 illustrates the developed PM emission estimation model, which consists of three main modules: (1) Parameter Identification Module; (2) DES Modeling Module; and (3) PM Evaluation Module. The detailed concepts for all modules are provided later. The rest of this paper is organized as follows. The next sections provide the knowledge background on emission quantification from construction equipment operations, followed by a theoretical description of EZStrobe. Then, each module of the PM emission estimation model is introduced sequentially. A case study of a highway construction project is then presented, before presenting the analytical results, discussion, and conclusion, respectively.

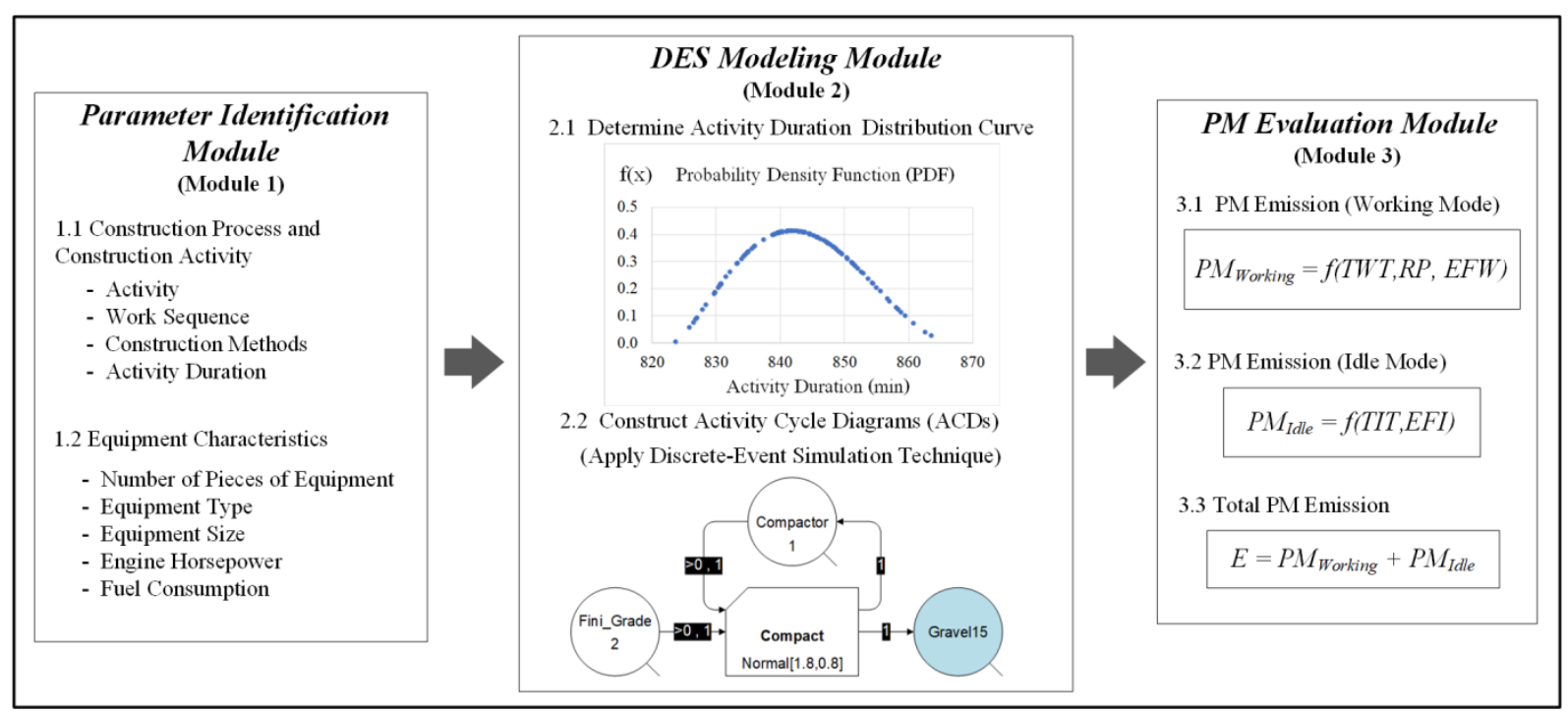

Figure 1. Schematic framework of PM emission estimation model 


\section{Literature on Emission Quantification of Heavy Equipment}

A substantial number of research studies and technical reports have stated the contribution of the construction industry to greenhouse gas (GHG) emissions due to the large amounts of gasoline and diesel fuel required for heavy equipment operations (e.g., [13, 18-21]). Among other GHGs, $\mathrm{CO}_{2}$ is the largest contributor to global warming [22], as a product of the chemical reaction of carbon from burning fossil fuel during the combustion process in equipment with oxygen in the atmosphere [18]. Additionally, the continued use of fossil fuel in heavy equipment operations leads to the critical environmental threat of PM emissions that seriously affect human health and urgently need a remedy $[5,6]$. However, the published literature has identified a lack of an effective approach or method in predicting emissions from on-site construction equipment before the execution phase of the construction process $[20,23]$. Thus, a new method is a pressing need for project owners, planners, and contractors to quantify the environmental impacts of their selected construction means and to raise attention toward achieving sustainability in this industry.

Generally, accurate emission assessment is best achieved when the direct measurement is executed onsite during construction, which is not always practical [24]. Furthermore, onsite direct measurement does not promote proactive implementation that requires active decision-making on the sustainability plan prior to its real execution. Consequently, several tools have been developed to facilitate a comprehensive estimation of airborne emissions from construction equipment operations, including the NONROAD model [25], OFFROAD model [26], Road Construction Emissions Model [27], and Carbon Footprint Estimation Tool [28]. Nevertheless, most of these models fundamentally adopt national or regional average data as being representative of various types of equipment that are not able to fully reflect the actual characteristics of a specific piece of equipment. The discrete-event simulation technique (DES) has emerged in academic and research fields of construction emissions estimation to consider the weighted-average emission factors and the operating hours of equipment $[13,14]$.

In addition to the working and idle times from the DES analysis, the emission factor is another important parameter for estimation. With respect to the types of emissions, the US EPA has provided the weighted-average emission factors for working-mode and idling-mode operations in several technical documents, such as [29] for exhaust emissions in non-road equipment and [30] for idling vehicle emissions. The gross vehicle weight $(\mathrm{GVW})$ classification and characteristics can be identified according to [31]. The values of PM-related emission factors can be presented as in Tables 1-2.

Table 1. Examples of non-road compression-ignition engines: exhaust emissions [29]

\begin{tabular}{|c|c|c|c|c|c|c|c|}
\hline $\begin{array}{c}\text { Rated Power } \\
(\mathbf{k W})\end{array}$ & Tier & Model Year & $\begin{array}{c}\text { PM } \\
(\mathrm{g} / \mathrm{kW}-\mathrm{hr})\end{array}$ & $\begin{array}{c}\text { Rated Power } \\
(\mathbf{k W})\end{array}$ & Tier & Model Year & $\begin{array}{c}\text { PM } \\
\text { (g/kW-hr) }\end{array}$ \\
\hline \multirow{6}{*}{$37 \leq \mathrm{kW}<56$} & 1 & $1998-2003$ & - & \multirow{6}{*}{$75 \leq \mathrm{kW}<130$} & 1 & $1997-2002$ & - \\
\hline & 2 & 2004-2007 & 0.40 & & 2 & 2003-2006 & 0.30 \\
\hline & 3 & 2008-2011 & 0.40 & & 3 & $2007-2011$ & 0.30 \\
\hline & 4 (Option 1) & $2008-2012$ & 0.30 & & & $2012-2013$ & 0.02 \\
\hline & 4 (Option 2) & 2012 & 0.03 & & 4 & \multirow{2}{*}{$2014+$} & \multirow{2}{*}{0.02} \\
\hline & 4 & $2013+$ & 0.03 & & & & \\
\hline \multirow{5}{*}{$56 \leq \mathrm{kW}<75$} & 1 & $1998-2003$ & - & \multirow{5}{*}{$130 \leq \mathrm{kW}<225$} & 1 & $1996-2002$ & 0.54 \\
\hline & 2 & 2004-2007 & 0.40 & & 2 & 2003-2005 & 0.20 \\
\hline & 3 & 2008-2011 & 0.40 & & 3 & 2006-2010 & 0.20 \\
\hline & \multirow{2}{*}{4} & 2012-2013 & 0.02 & & \multirow{2}{*}{4} & 2011-2013 & 0.02 \\
\hline & & $2014+$ & 0.02 & & & $2014+$ & 0.02 \\
\hline
\end{tabular}

Table 2. Average idle emissions for heavy-duty diesel vehicles by GVW class [30]

\begin{tabular}{|c|c|c|c|c|c|c|c|c|c|}
\hline Pollutant & Units & IIb & III & IV & V & VI & VII & VIIIa & VIIIb \\
\hline \multirow{2}{*}{$\mathrm{PM}_{2.5}$} & $\mathrm{~g} / \mathrm{hr}$ & 1.103 & 1.010 & 1.065 & 1.008 & 1.069 & 1.093 & 1.070 & 1.114 \\
& $\mathrm{~g} / \mathrm{min}$ & 0.018 & 0.017 & 0.018 & 0.017 & 0.018 & 0.018 & 0.018 & 0.019 \\
\hline \multirow{2}{*}{$\mathrm{PM}_{10}$} & $\mathrm{~g} / \mathrm{hr}$ & 1.199 & 1.098 & 1.157 & 1.095 & 1.162 & 1.188 & 1.163 & 1.211 \\
& $\mathrm{~g} / \mathrm{min}$ & 0.020 & 0.018 & 0.019 & 0.018 & 0.019 & 0.020 & 0.019 & 0.020 \\
\hline
\end{tabular}




\section{Discrete-event Simulation and EZStrobe}

The DES technique has been widely applied in the research area of construction engineering and management throughout the life cycle of construction projects to facilitate decision-making by construction planners [12,17,32]. In addition to a lower implementation cost, DES has little effect on the existing construction performance and plan that advises the use of the DES technique for computational analysis instead of interrupting on-site field operations [33].

Several DES tools have been developed to facilitate a simulation of complex system modeling and support decision making, such as CYCLONE [34], EZStrobe [17], STROBOSCOPE [35], and visual SLAM [36]. However, among those simulation tools, EZStrobe has been widely recognized because of its capabilities of being easy-to-learn and requiring little analysis effort [17], due to the development of a Microsoft Visio interface for model formulation. The simulation modeling requires the construction of Activity Cycle Diagrams (ACDs) that present all basic modeling elements (activities, resources, and interactions) of the systematic network in graphical format. For a basic problem, these elements are commonly represented using different shapes in one of the following elements: Combi, Normal, Queue, Link, or Fork. The first two elements represent a construction activity, such as material loading, hauling, compacting. While Combi is defined as a construction activity under the availability of the resources, Normal represents the unconstrainted type of construction activity starting upon the completion of preceding activities. Next, Queue is the third element specifying the availability of resources in performing an activity, such as material, labor, and equipment. The rest two elements introduce the interactions between elements, as Link is fundamental in representing general connectivity, and Fork presents a probabilistic branch selection. To construct the ACDs, the data associated with the work quantity, work breakdown, activity sequence, activity duration, and resource type and its unitization is acquired from several available sources, including drawings, specifications, site investigation, and contractor interview.

The start condition for the simulation run is determined under the availability of resource amounts in a Queue. The operational process is repetitively performed until the termination condition is satisfied, which is defined in terms of either a limit on simulation time or the number of times a particular activity starts. EZStrobe also allows the modeler to parameterize the constructed model and customized the required output with the defined formula, with its capability of graphical and interactive animation for model verification. More detailed instructions and rules for DES model construction can be further found in [17]. Figure 2 illustrates an example of an EZStrobe ACD for the base layer construction in this study, retrieved from [37].

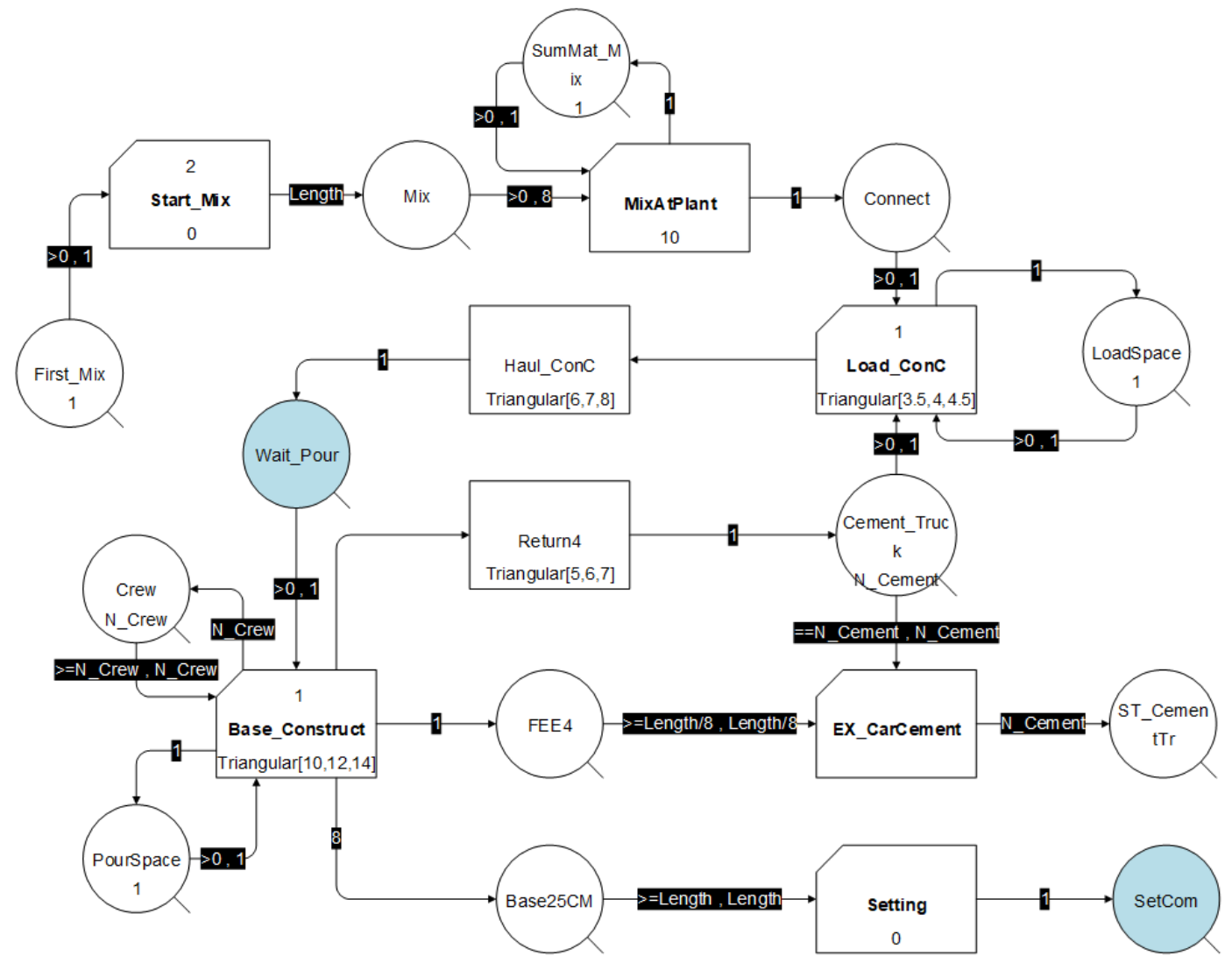

Figure 2. Example of EZStrobe Activity Cycle Diagram 


\section{Development of the PM Emission Estimation Model}

This paper reports on a PM emission estimation model that is composed of three consecutive modules. First, the parameter identification module identifies all the essential data for the DES model construction and gathers all relevant data from the literature and technical documents. The required data is associated with all construction activities under the scope of analysis, including the construction process, construction activity, work sequence, work quantity, resource, and work conditions. Notably, the resources considered here are the different types and numbers of pieces of heavy-duty equipment used on the construction jobsite. The engine characteristics of equipment are important for the productivity calculation, which has a direct impact on the activity duration and therefore on total project duration. The focus of the construction resources in this study is diesel-engine combustion equipment due to its high impact on PM emissions released to the atmosphere. The data acquired at this stage will be then used to formulate the ACD that is a fundamental component of the DES technique

The second module, namely the DES modeling module, aims to simulate the complex construction activities and processes using the DES technique. The procedure is executed using two steps. The first step determines the activity duration distribution curve that represents the variation of an activity duration in the entire project due to uncertainty. The distribution of duration of an activity was statistically analyzed based on the site data collection. The simulation modeling was next established with the development of the ACD as the graphical presentation of the complex systematic network. Finally, the additional mathematical formulas for estimating the emissions are introduced and incorporated into the DES under the third module, namely the PM evaluation module.

Generally, PM emission in construction represents the quantity of a PM pollutant released due to a construction activity. An amount of emission is typically referred to as the weight of pollutant emitted to the atmosphere per one unit, which can be either in terms of unit weight, volume, or activity duration [38]. The document introduces the general estimation formulae that is later applied for calculating emission quantities of various types of gases.
This concept of the US EPA has been adopted for $\mathrm{CO}_{2}$ emission estimation with modification to suit the DES algorithms in [15] and is proposed for PM emission calculation, as presented in (1).

$$
\begin{array}{r}
\sum_{i=1}^{I} \sum_{j=1}^{J} \sum_{k=1}^{K} W T_{i j} \times R P_{i j} x E F W_{k}+ \\
\sum_{i=1}^{I} \sum_{j=1}^{J} \sum_{k=1}^{K} I T_{i j} x R_{i j} x E F I_{k}
\end{array}
$$

where $E=$ total $\mathrm{PM}$ emissions $(\mathrm{g}) ; W T_{i j}=$ working hour (hr) of equipment $i$ on activity $j$; IT $i j=$ idle time (hr) of equipment $i$ on activity $j ; R P_{i j}=$ rated engine power of equipment $i$ on activity $j(\mathrm{~kW}) ; E F W_{k}=$ emission factor $(\mathrm{g} / \mathrm{kW}-\mathrm{hr})$ of particulate matter (PM) type $k$ at working stage; and $E F I_{k}=$ emission factor $(\mathrm{g} / \mathrm{kW}-\mathrm{hr})$ of PM type $k$ at idling stage. The parameter $k$ represents the PM type $\left(k=1\right.$ for $\mathrm{PM}_{2.5}$ and $k=2$ for $\left.\mathrm{PM}_{10}\right)$.

\section{Case Study}

This section develops a case study of a rigid pavement project constructed in Thailand and is used here to demonstrate the performance and capabilities of the developed model in estimating PM emissions from heavy-duty equipment operations. The data of the application example were adopted according to the extension part of the on-ground structure linked between the existing highway and urban local road. The project was constructed using three main structural layers: $40 \mathrm{~cm}$ subbase, $25 \mathrm{~cm}$ base, and $5 \mathrm{~cm}$ surface layer. The $40 \mathrm{~cm}$ subbase layer was divided into three sublayers consisting of $15 \mathrm{~cm}$ sand, $15 \mathrm{~cm}$ gravel, and $10 \mathrm{~cm}$ sand, respectively. Different types of equipment were used in the construction of each main layer. The conceptual approach of using the DES to simulate the construction process in the case study is provided in [37]. The data for estimating emissions of $\mathrm{PM}_{2.5}$ and $\mathrm{PM}_{10}$ in this paper are shown in Table 3. The equipment characteristics (engine power, tier, vehicle class, and gross weight) were acquired from Caterpillar Manual Handbook [39]. The amount of total PM emissions was adopted from the emission rate in [29], while the idle emission rates for $\mathrm{PM}_{2.5}$ and $\mathrm{PM}_{10}$ were retrieved from [30]. In addition, the proportional ratio between $\mathrm{PM}_{10} / \mathrm{PM}_{2.5}$ at the working stage was assigned according to [30] and [40].

Table 3. Average idle emissions for heavy-duty diesel vehicles by GVW class [30]

\begin{tabular}{|c|c|c|c|c|}
\hline \multirow{2}{*}{ Equipment } & Rated Power & GV Class & \multicolumn{2}{|c|}{$\begin{array}{c}\text { PM Emission Rate } \\
(\mathrm{g} / \mathrm{kW}-\mathrm{hr})\end{array}$} \\
\cline { 2 - 5 }$(\mathrm{g} / \mathrm{hr})$
\end{tabular}




\section{Results and Discussion}

This section discusses the results from applying the developed PM emission estimation model in the case study. The analyses were performed to investigate the model's capabilities in evaluating diesel exhaust emissions from construction equipment and therefore effectively identifying an equipment productivity improvement strategy. The analysis was initially simulated based on the number of pieces of equipment used in the case project based on the \% utilization of each type of equipment, as shown in Table 4. The results indicated unbalanced utilization of 19.6 and $99.9 \%$ for the excavators and trucks, respectively, highlighting the ineffectiveness of the excavation and hauling activities. Therefore, this paper places emphasis on the interaction between the excavators and trucks and preliminarily suggests how to arrange an effective configuration.

The outcome of the simulation analysis was determined as equipment fleet utilization rate, project duration, and PM emission due to the equipment operations in the project construction. The number of different excavators and that of trucks were varied to examine: (1) the impacts of different crew configuration strategies on equipment utilization rate; (2) the impacts of different crew configurations on project duration; (3) the impacts of different crew configuration strategies on total PM emission, and average hourly PM emission; (4) and potential combination sets of equipment according to the outcomes' relationships and contractor's weight preference.

Accordingly, further investigation assigned different numbers of excavators (up to three). Figure 3 illustrates the utilization rate of the different sets of equipment fleet. The case study proposed the highest utilization rate at $87.6 \%$. For one excavator, this rate increased when the number of trucks increased until reaching maximum utilization at nine trucks in the fleet. The trend suggests that a similar finding for two and three excavators, but with a less reduction slope.

Table 4. Initial number of pieces of equipment and $\%$ utilization for case study

\begin{tabular}{|c|c|c|c|c|c|c|c|c|}
\hline Equipment & Excavator & 6-Wheeled Truck & Grader & Compactor & Cement truck & Asphalt distributor & Paver & Tire roller \\
\hline Number (pieces) & 1 & 2 & 1 & 1 & 5 & 1 & 1 & 1 \\
Utilization (\%) & 19.6 & 99.9 & 46.8 & 37.7 & 94.8 & 100 & 100 & 100 \\
\hline
\end{tabular}

\section{Fleet utilization (\%)}

90

85

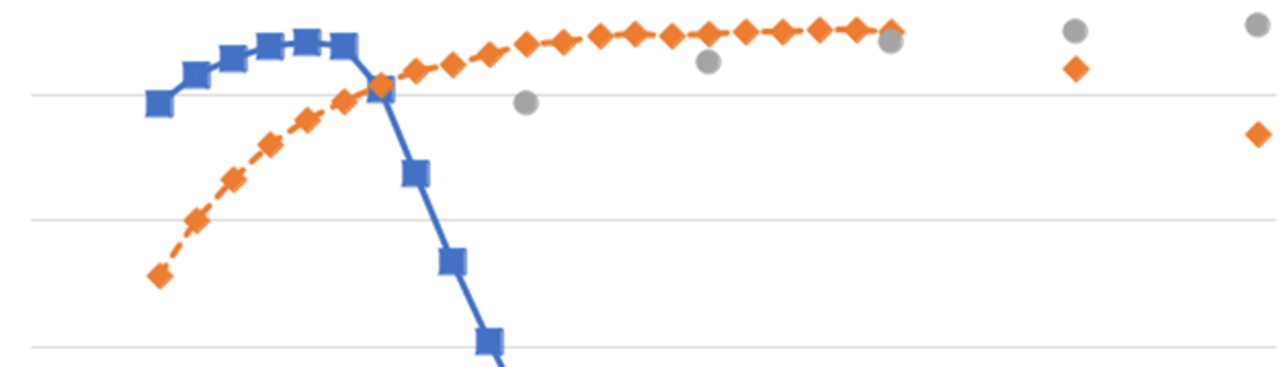

75

70

1 Excavator

- 2 Excavators

-3 Excavators

65

60

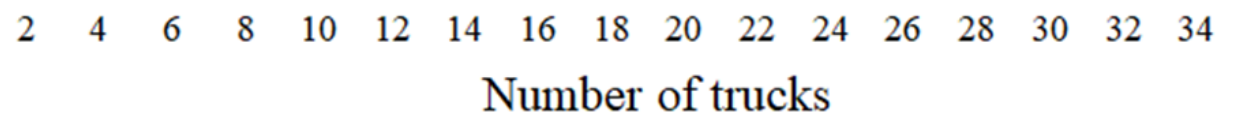

Figure 3. Utilization rate of equipment fleet 
The study revealed that a substantial number of trucks at 24 and more than 35 trucks were required for two and three excavators, respectively, to achieve a high utilization. This also indicated the overwhelming number of trucks are required for the optimal configuration. Figure 4 presents the impacts on total project duration, with a steeper slope for a lower number of trucks (see Group\#1, Figure 4). Where the trend is horizontal, there is little difference in the duration as the appropriate numbers of trucks and excavators were already assigned to the fleet (see Group\#2, Figure 4). The results showed that the minimum total project duration was around 313 hours, given fixed numbers of pieces for the other equipment types shown in Table 4.

Considering both Figures 3 and 4, the findings show that increasing the number of trucks after an optimal point is probably not effective in terms of resource usage and project cost, as the total project duration could not be improved by this, despite the additional expenditure.
Furthermore, allocating excess trucks could reduce effective fleet utilization. Apparently, using two excavators and 25 trucks reduced the duration by only 10 hours (322 312 hours), or less than $3 \%$ from the initial plan, compared to the substantial contribution for an optimal or near optimal configuration. Therefore, once reaching the optimal combination for excavators and trucks, the total project duration can be reduced by increasing resources in other critical activities instead.

Focusing on the PM emissions, similar trends were revealed for the amounts of $\mathrm{PM}_{2.5}$ and $\mathrm{PM}_{10}$ emissions, as exemplified for one excavator in Figure 5. In this case, these amounts were likely to decrease corresponding to a shorter duration due to more effective equipment fleet utilization patterns. The lowest $\mathrm{PM}_{2.5}$ emission occurred when 9-10 trucks were used; likewise, for the $\mathrm{PM}_{10}$ emission. The results indicated that the magnitude of $\mathrm{PM}_{10}$ could triple $\mathrm{PM}_{2.5}$ for the same crew configurations, consistent with the proportion mentioned in [40].

\section{Duration (hour)}

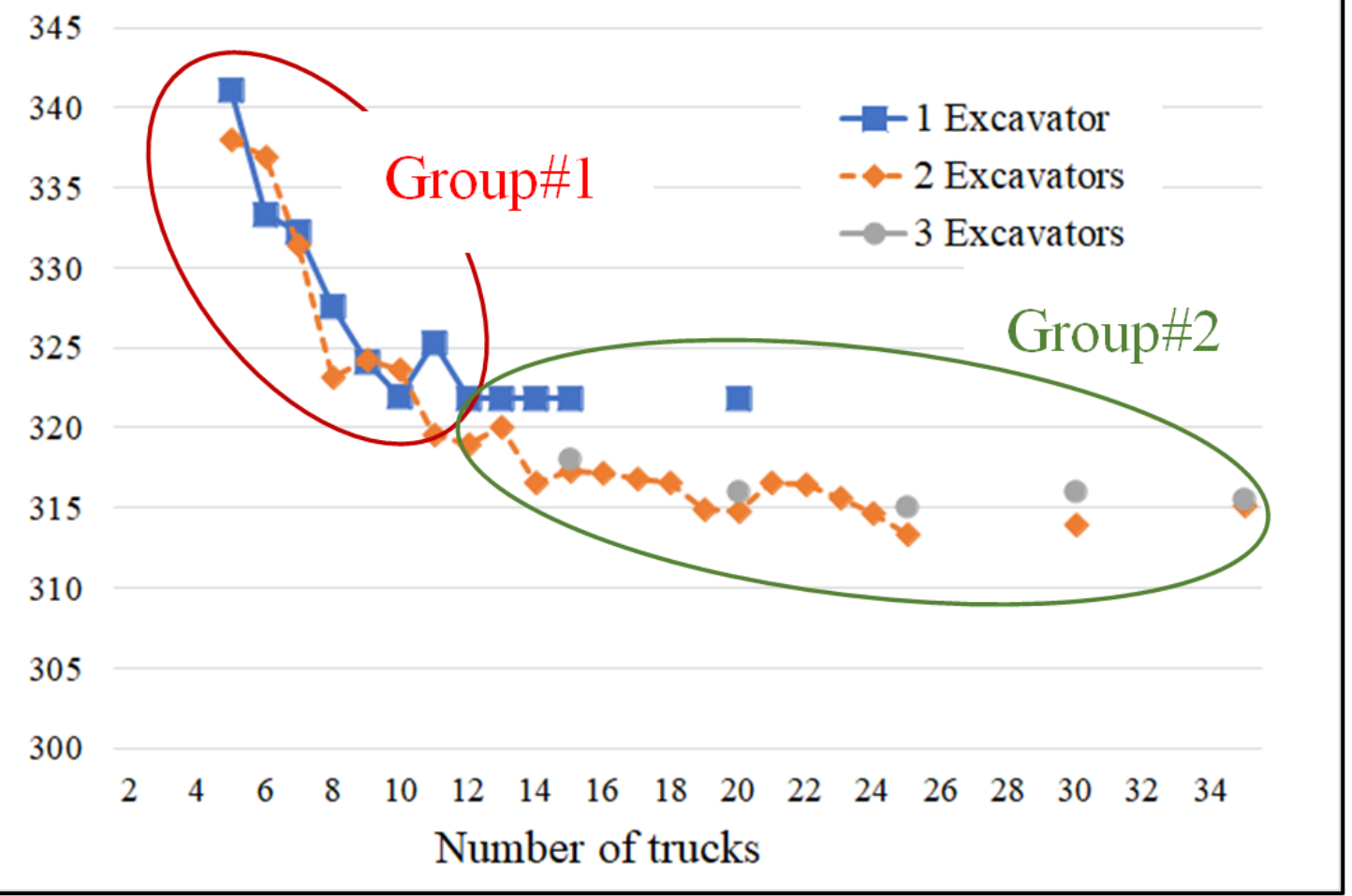

Figure 4. Total project duration of equipment fleet 


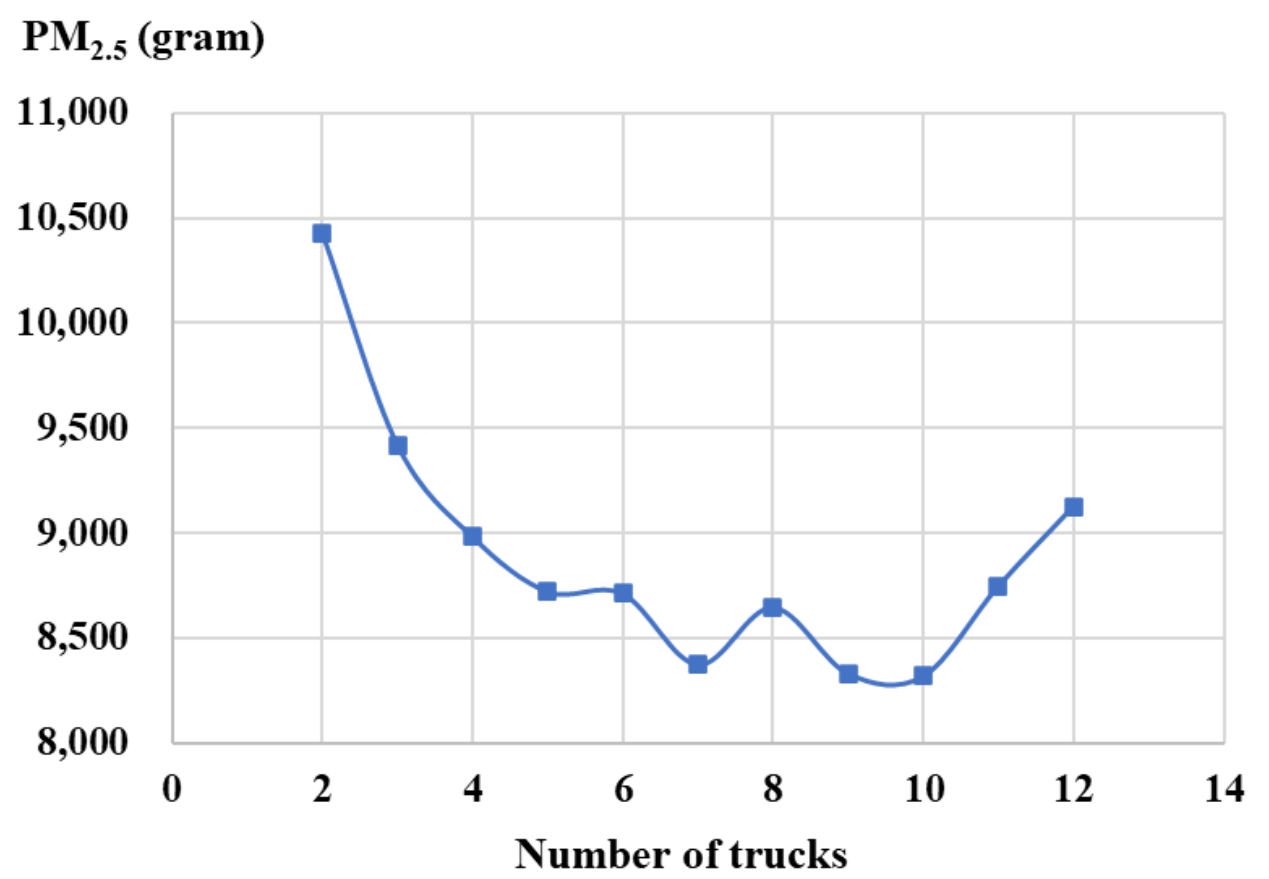

(a)

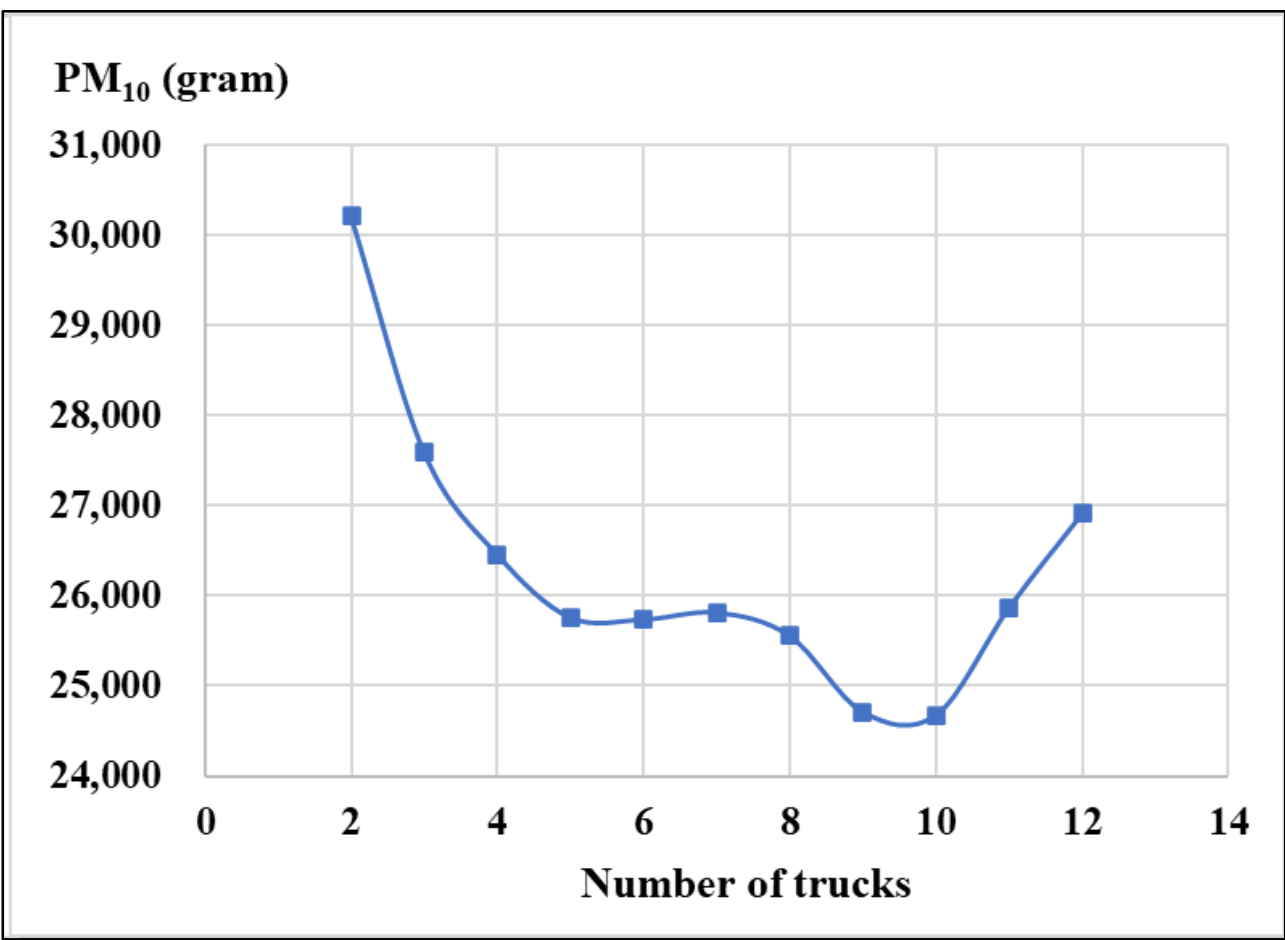

(b)

Figure 5. $\mathrm{PM}_{2.5}$ (a) and $\mathrm{PM}_{10}$ (b) emissions of different equipment fleets with one excavator assigned 


\section{Total PM (gram)}

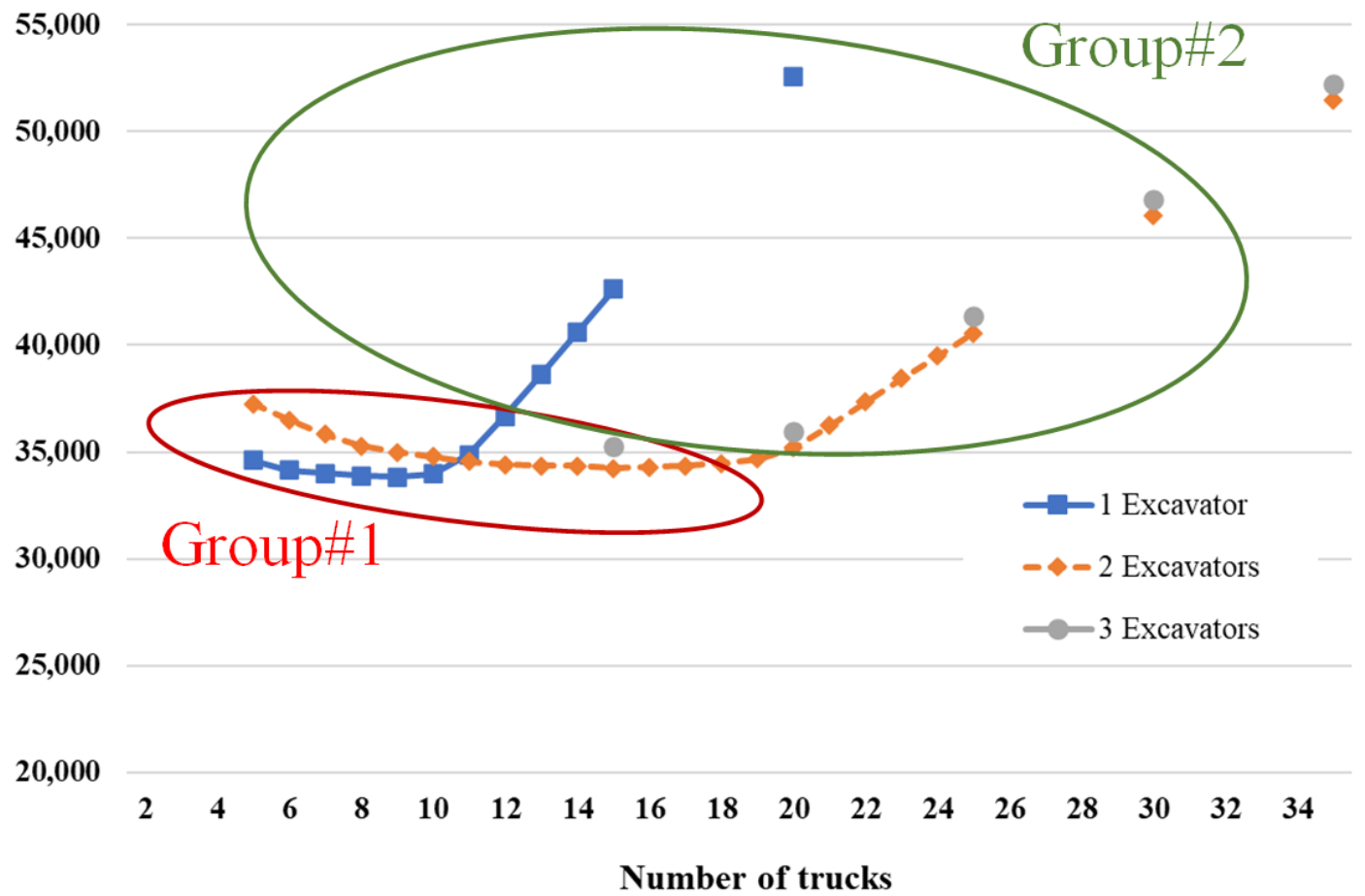

Figure 6. Total PM emissions of equipment fleet

\section{Hourly PM (gram/hour)}

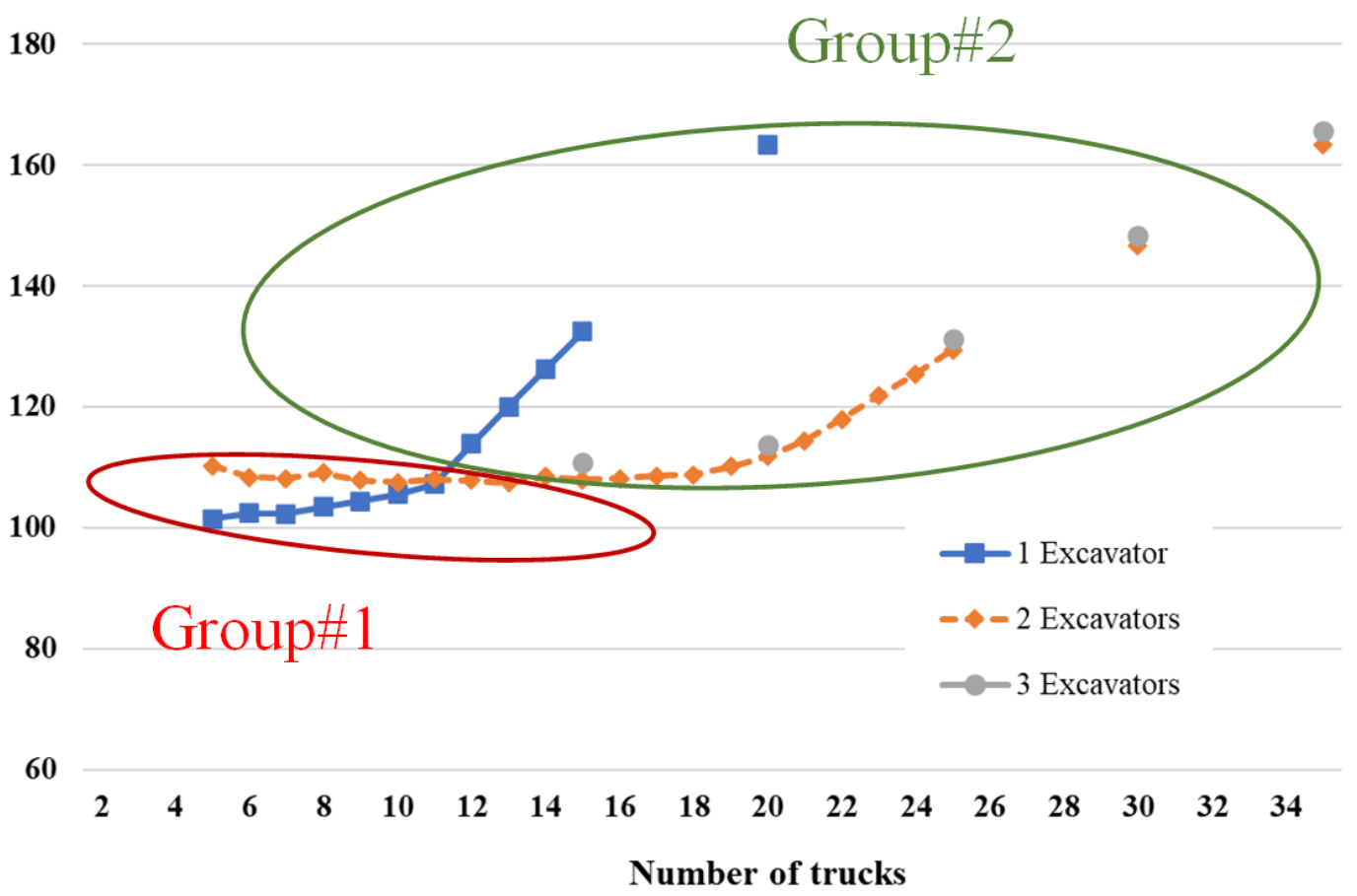

Figure 7. Hourly PM emissions of equipment fleet 


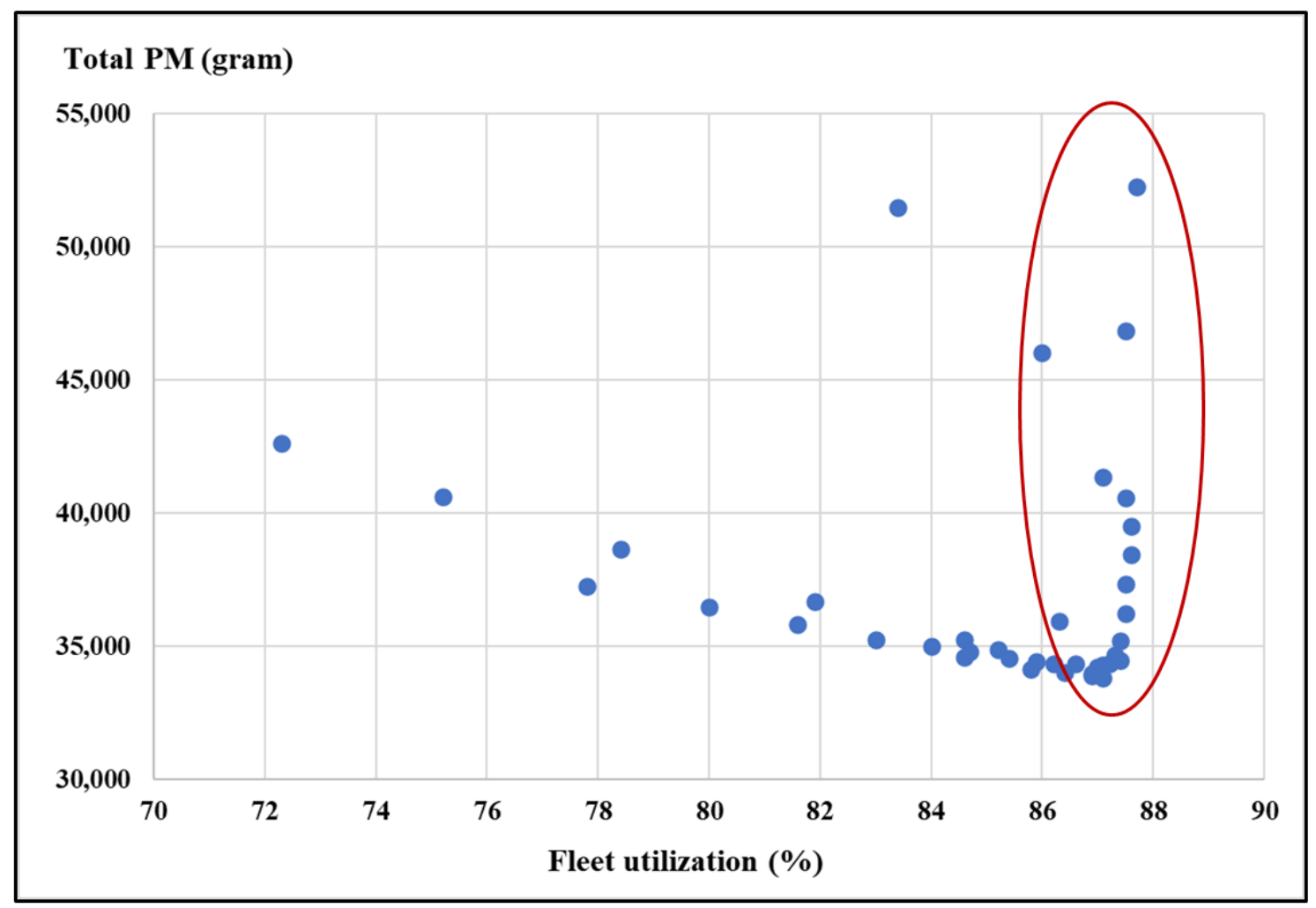

Figure 8. Correlation between total PM emissions and equipment fleet utilization

Figures 6 and 7 demonstrate the total and hourly PM emissions throughout the construction period. At the optimal point, both figures depict reduced emission rates for a lower number of trucks, while an excessive number of trucks beyond the optimal point leads to substantial emission increases. This is noticeable from the different slopes of Group\#1 and Group\#2 in the figures. In addition, similar trends for the total and hourly PM emissions resulted, though with a slight difference for Group\#1 (left hand side of the optimal point) because of the magnitudes of total PM emissions and project durations at different configurations. On the other hand, Group\#2 in both figures presented indifferent trends due to the comparability of project durations among all configurations in total.

Furthermore, the total PM emissions and fleet utilization rates in all the analyzed configurations were plotted (Figure 8) so conclusions could be drawn, where all points in the red circle indicate a high rate of fleet utilization (more than 86\%). However, some configurations still produced high emissions, demonstrating that only considering equipment utilization, as the conventional criterion for productivity improvement, could not always satisfy the sustainability goal in alleviating the PM emissions from the construction site. The construction planners are required to simultaneously improve fleet utilization and select appropriate and green equipment for their operations. Therefore, the potential configurations can be primarily decided under the highest point in the equipment rate utilization plot, along with the consideration of the lowest points from the project duration and PM emissions plots.

\section{Conclusions}

This paper introduced a development of the PM emission estimation model by integrating an application of the discrete-event simulation (DES) technique with environmental impact evaluation. The developed model contained three main modules: (1) Parameter Identification; (2) DES Modeling; and (3) PM Evaluation. Overall, the model aims to promote simplicity and practicality based on the current body of knowledge of PM construction-oriented emissions that have recently emerged. The results were analyzed to present the capabilities and performance of the developed model in estimating the PM emissions from construction equipment and to further support decision making in determining the optimal configuration for a sustainable equipment fleet. The findings revealed that excess trucks in the activities could result in ineffective crew management and unnecessary additional project expenses without shortening the project duration and reducing environmental impacts. After reaching the optimal crew configuration for the excavators and trucks, the project duration and emissions can be decreased by allocating additional pieces of equipment to the other critical linear activities. 
Furthermore, the study identified that considering only equipment utilization would not always satisfy project sustainability goals. Both improving fleet utilization and achieving proper green equipment characteristics are necessary for sustainability.

Nevertheless, future work should address the limitations on some types of data used in the paper, such as equipment characteristics and fuel consumption that can be realistically applied in the analysis. In addition, the proposed model can be extended to other types of large-scale infrastructure projects, such as flexible pavements, dams, and bridge construction, to identify the impacts of equipment operations on the environment. The model can also further facilitate decision making regarding resource allocation by being integrated with the aspects of cost, time, and quality.

\section{Acknowledgments}

This research was supported by the Faculty of Engineering at Kamphaeng Saen and Kasetsart University (Kamphaeng Saen Campus), Thailand. However, any opinions, findings, and recommendations written in this paper are those of the authors and do not necessarily reflect any opinions of the funding agency.

\section{REFERENCES}

[1] C. Loftus, M. Yost, P. Sampson, G. Arias, E. Torres, V.B. Vasquez, P. Bhatti, C. Karr. Regional PM2.5 and asthma morbidity in an agricultural community: a panel study, Environmental Research, Vol.136, 505-512, 2015.

[2] C.A. Pope III, D.W. Dockery. Health effects of fine particulate air pollution: lines that connect, Journal of the Air \& Waste Management Association, Vol.56, No.6, 709-742, 2006.

[3] H. Zhan, Q. Li, K. Zhao, L. Zhang, Z. Zhang, C. Zhang, L. Xiao. Evaluating PM2.5 at a construction site using terahertz radiation, IEEE Transactions on Terahertz Science and Technology, Vol.5, No.6, 1028-1034, 2015.

[4] US EPA, Particulate Matter Emissions, Report on the Environment, Online available from https://cfpub.epa.gov > roe > indicator_pdf.

[5] K. Ketchman, M. Bilec. Quantification of particulate matter from commercial building excavation activities using life-cycle approach, Journal of Construction Engineering and Management, Vol.139, No.12, A4013007, 2013.

[6] G.E. Muleski, C. Cowherd Jr, J.S. Kinsey. Particulate emissions from construction activities, Journal of the Air \& Waste Management Association, Vol.55, No.6, 772-783, 2005.

[7] J.C. Martinez, P.G. Ioannou. General-purpose systems for effective construction simulation, Journal of Construction
Engineering and Management, Vol.125, No.4, 265-276, 1999.

[8] M. Lu. Simplified discrete-event simulation approach for construction simulation, Journal of Construction Engineering and Management, Vol.129, No.5, 537-546, 2003.

[9] J.C. Martinez. Methodology for conducting discrete-event simulation studies in construction engineering and management, Journal of Construction Engineering and Management, Vol.136, No.1, 3-16, 2010.

[10] P. Srisurin. Development of Simulation Models for the Cement Loading Process at a Cement Plant, M.S. thesis, University of Hawaii at Manoa, Honolulu, Hawaii, 2013.

[11]N. Athigakunagorn. Determining the effectiveness of asphalt concrete overlays on rigid pavement using discrete-event simulation, Engineering Journal, Vol.21, No.4, 171-182, 2017.

[12] N. Athigakunagorn, C. Limsawasd. Effective crew allocation using discrete-event simulation: building scaffolding case study in Thailand, Engineering Journal, Vol.24, No.4, $143-156,2020$

[13]C. Ahn, W. Pan, S.H. Lee, F. Pena-Mora. Enhanced Estimation of Air Emissions from Construction Operations based on Discrete-event Simulation, International Conference on Computing in Civil and Building Engineering (ICCCBE) 2010, Nottingham, UK, June 30-July 2, 2010.

[14] C. Ahn, H. Xie, S.H. Lee, S. Abourizk, F. A. Pena-Mora. Sustainability Analysis of Tunnel Construction Processes using Collaborative Tunneling Simulation, Construction Research Congress 2010, Banff, Alberta, Canada, May 8 $10,2010$.

[15] C. Limsawasd, N. Athigakunagorn. An application of discrete-event simulation in estimating emissions from equipment operations in flexible pavement construction projects, Engineering Journal, Vol.21, No.7, 197-211, 2017.

[16] J. Somboonpisan, C. Limsawasd. Environmental weight for bid evaluation to promote sustainability in highway construction projects, Journal of Construction Engineering and Management, Vol.147, No.4, 04021013, 2021.

[17] J. C. Martinez. EZStrobe: General-purpose Simulation System based on Activity Cycle Diagrams, The 33rd Conference on Winter Simulation, IEEE Computer Society, Arlington, Virginia, December 9 - 12, 2001.

[18]H.G. Avetisyan, E. Miller-Hooks, S. Melanta. Decision models to support greenhouse gas emissions reduction from transportation construction projects, Journal of Construction Engineering and Management, Vol. 138, No.5, 631-641, 2012.

[19] A.L. Sharrard, H.S. Matthews, M. Roth. Environmental implications of construction site energy use and electricity generation, Journal of Construction Engineering and Management, Vol.133, No.11, 846-854, 2007.

[20] M.L. Trani, B. Bossi, M. Gangolells, M. Casals. Predicting fuel energy consumption during earthworks, Journal of Cleaner Production, Vol.112, 3798-3809, 2016.

[21]P. Truitt. Quantifying Greenhouse Gas Emissions from Key Industrial Sectors in the United States, United States Environmental Protection Agency, Washington, DC, 2008. 
[22]US EPA. Greenhouse Gas Emissions: Overview of Greenhouse Gases, Online available from https://www.epa.gov/ghgemissions/overview-greenhouse-ga ses

[23] H.S. Jassim, W. Lu, T. Olofsson. Assessing energy consumption and carbon dioxide emissions of off-highway trucks in earthwork operations: An artificial neural network model, Journal of Cleaner Production, Vol.198, 364-380, 2018.

[24]H. Zhang. Discrete-event simulation for estimating emissions from construction processes, Journal of Management in Engineering, Vol.31, No.2, 04014034, 2015.

[25] US EPA. EPA NONROAD Model Updates of 2008 "NONROAD2008", Online available from https://nepis.epa.gov/Exe/ZyPDF.cgi?Dockey=P100AKH1. pdf

[26] ARB. Mobile Source Emissions Inventory -- Off-road Diesel Vehicles, Air Resources Board, Online available from https://ww3.arb.ca.gov/msei/ordiesel.htm

[27] M. P. Lewis. Estimating Fuel Use and Emission Rates of Nonroad Diesel Construction Equipment Performing Representative Duty Cycles. Ph.D. thesis, North Carolina State University, Raleigh, NC, USA, 2009.

[28] S. Melanta, E. Miller-Hooks, H.G. Avetisyan. Carbon footprint estimation tool for transportation construction projects, Journal of Construction Engineering and Management, Vol.139, No.5, 547-555, 2013.

[29] US EPA. Nonroad Compression-ignition Engines: Exhaust Emission Standards. Office of Transportation and Air Quality, EPA-420-B-16-022, United States Environmental Protection Agency, Washington, DC, 2016.

[30]US EPA. Emission Facts: Idling Vehicle Emissions for Passenger Cars, Light-duty Trucks, and Heavy-duty Trucks, Office of Transportation and Air Quality, EPA420-F-08-025, United States Environmental Protection Agency, Washington, DC, 2008.
[31]US EPA. Vehicle Weight Classifications for the Emission Standards Reference Guide, Online available from https://www.epa.gov/emission-standards-reference-guide/ve hicle-weight-classifications-emission-standards-reference-g uide

[32] S.D. Smith, J.R. Osborne, M.C. Forde. Analysis of earth-moving systems using discrete-event simulation, Journal of Construction Engineering and Management, Vol.121, No.4, 388-396, 1995.

[33] A. M. Law. Simulation Modeling and Analysis (Vol. 4), McGraw-Hill, New York, 1991.

[34] D.W. Halpin. CYCLONE-method for modeling job site processes, Journal of the Construction Division, Vol.103, No.3, 489-499, 1977.

[35] J. C. Martinez. STROBOSCOPE: State and Resource Based Simulation of Construction Processes. Ph.D. dissertation, University of Michigan, Ann Arbor, Michigan, 1996.

[36] A. A. B. Prisker, J. J. O’Reilly. Simulation with Visual SLAM and AweSim, Wiley, New York, 1997.

[37] J. Somboonpisan, C. Limsawasd, N. Athigakunagorn. Carbon Footprint Assessment for Resilient Infrastructure Construction using Discrete-event Simulation, The 8th Civil Engineering Conference in the Asian Region (CECAR 8), Tokyo, Japan, April 16 - 19, 2019.

[38] US EPA. AP-42, Fifth Edition Compilation of Air Pollutant Emissions Factors, Volume 1: Stationary Point and Area Sources, Online available from https://www.epa.gov/air-emissions-factors-and-quantificatio n/ap-42-compilation-air-emissions-factors $\# 5$ thed

[39]CAT. Caterpillar Products, Online available from https://www.cat.com/en_US/products.html

[40] M. Ferm, K. Sjöberg. Concentrations and emission factors for $\mathrm{PM}_{2.5}$ and $\mathrm{PM}_{10}$ from road traffic in Sweden, Atmospheric Environment, Vol. 119, 211-219, 2015. 